Sharif University of Technology
Scientia Iranica
SCIENTIA
IRAN ICA
http://scientiairanica.sharif.edu

\title{
A regression-based approach to the prediction of crest settlement of embankment dams under earthquake shaking
}

\author{
H. Javdanian*, H.R. Zarif Sanayei, and L. Shakarami \\ Department of Civil Engineering, Shahrekord University, Shahrekord, Iran.
}

Received 20 February 2018; received in revised form 14 March 2018; accepted 24 April 2018

\author{
KEYWORDS \\ Embankment dam; \\ Earthquake; \\ Crest settlement; \\ Support vector \\ regression; \\ Predictive model.
}

\begin{abstract}
The settlement of embankment dams is among the many major damages caused by earthquakes that, eventually, leads to dam instability. Therefore, an accurate assessment of the seismic settlement of embankment dams is of particular concern. This study aims to evaluate the settlement of embankment dams subjected to earthquake loads using regression-based methods. wide-ranging cases of real data on crest settlement of embankment dams caused by earthquakes were analyzed. Yield acceleration of dam $\left(a_{y}\right)$, maximum horizontal earthquake acceleration $\left(a_{\max }\right)$, fundamental period of dam body $\left(T_{d}\right)$, predominant period of earthquake $\left(T_{p}\right)$, and earthquake magnitude $\left(M_{w}\right)$ were considered as the most influential parameters that affect the seismic crest settlement of embankment dams. By applying Support Vector Regression (SVR) and Multiple Linear Regression (MLR) methods, two models were developed to estimate the earthquake-induced settlement of embankment dams. Subsequently, sensitivity analysis was conducted in order to assess the behavior of the proposed models under different conditions. Finally, the accuracy of the proposed models was compared with the existing relationship for the estimation of earthquake-induced crest settlement of embankment dams. Although both MLR- and SVR-based models enjoy acceptable accuracy in the estimation of the crest settlement of embankment dams under earthquake loading, the SVR-based model has higher accuracy.

(C) 2020 Sharif University of Technology. All rights reserved.
\end{abstract}

\section{Introduction}

An inaccurate assessment of the behavior of embankment dams subjected to seismic vibrations caused by earthquakes can lead to catastrophic damages. The pseudo-static method, sliding block method, and numerical methods are common techniques to estimate seismic deformations of embankment dams [1]. Newmark [2] proposed the sliding block method as the first approach to the evaluation of the earthquake-induced

\footnotetext{
*. Corresponding author.

E-mail address: javdanian@eng.sku.ac.ir (H. Javdanian)
}

doi: $10.24200 /$ sci. 2018.50483 .1716 deformations of soil slopes. In this method, the sliding mass was considered as a rigid block such that an input acceleration (caused by the earthquake) greater than the yield acceleration forced the block to move [3]. Makdisi and Seed [4] modified the sliding block model and considered the response acceleration of the sliding mass as the input acceleration. They then used this acceleration to calculate the displacements.

The behavior of embankment dams under earthquake shaking has been studied by many researchers [5-13]. Applying physical modeling and conducting centrifuge experiments, Park and Kim [14] and Kim et al. [15] investigated the behavior of rockfill dams subjected to earthquake loads. Based on the seismic deformations in different embankment dams under 
Table 1. Statistical parameters of database used in the present study.

\begin{tabular}{lccccccccccc}
\hline & \multicolumn{10}{c}{ Parameter } \\
\cline { 2 - 11 } Statistical index & $\boldsymbol{a}_{\boldsymbol{y}}(\mathrm{g})$ & $\boldsymbol{a}_{\max }(\mathrm{g})$ & $\boldsymbol{a}_{\boldsymbol{y}} / \boldsymbol{a}_{\max }$ & $\boldsymbol{T}_{\boldsymbol{d}}(\mathbf{s e c})$ & $\boldsymbol{T}_{\boldsymbol{p}}(\mathbf{s e c})$ & $\boldsymbol{T}_{\boldsymbol{d}} / \boldsymbol{T}_{\boldsymbol{p}}$ & $\boldsymbol{M}_{\boldsymbol{w}}$ & $\boldsymbol{H}(\mathbf{m})$ & $\boldsymbol{S}(\mathbf{m})$ & $\boldsymbol{S} / \boldsymbol{H}$ \\
\hline Minimum & 0 & 0.004 & 0 & 0.05 & 0.25 & 0.117 & 0.7 & 2.5 & 0.001 & $8.3 \mathrm{e}-6$ \\
Maximum & 0.55 & 0.9 & 50 & 2.74 & 0.96 & 10.96 & 8.3 & 235 & 32 & 1.359 \\
Mean & 0.162 & 0.285 & 2.285 & 0.581 & 0.378 & 1.672 & 6.938 & 42.221 & 1.321 & 0.11 \\
Standard deviation & 0.11 & 0.211 & 6.428 & 0.437 & 0.131 & 1.391 & 1.098 & 40.240 & 3.757 & 0.238 \\
\hline
\end{tabular}

earthquake vibrations, Singh et al. [16,17] showed that the yield acceleration of the dam and the maximum earthquake acceleration were among the most important parameters that affect the seismic behavior of embankment dams. They also found that the effect of vertical component of earthquake acceleration was negligible in assessing the behavior of dams.

The accurate assessment of the behavior of embankment dams under various loads is among the important issues to be considered in the initial design of these large structures. Therefore, estimating the settlement of embankment dams subjected to earthquake shaking requires accurate models.

As powerful tools, soft computing methods have been successfully employed in different fields of geotechnical engineering such as predicting dynamic properties of soils [18-21], behavior of stabilized soils [22-24], liquefaction potential of soil deposits [25], ground motion duration [26], scour depth [27-31], soil friction angle [32], and collapse potential of compacted soils [33].

In recent years, the SVR-based models have managed to offer accurate assessments regarding the geotechnical problems (e.g., [34-37]). The phenomena related to soil environments, as well as the earthquakeinduced loadings, are highly complex [38-40]. Therefore, the application of advanced computational methods for the estimation of the behavior of embankment dams subjected to earthquake shaking can be an effective step in reducing the uncertainties in the prediction of seismic behaviors and, subsequently, safe designing of dams.

In this study, a large set of seismic crest settlements of different embankment dams was collected and analyzed. The most important parameters affecting the earthquake-induced crest settlement were determined. The Support Vector Regression (SVR) method and Multiple Linear Regression (MLR) method were used to develop models for the prediction of seismic settlement of embankment dams. Subsequently, sensitivity analysis was conducted in order to investigate 1 ) the behavior of the proposed models under different conditions and 2) the effect of different parameters on the crest settlements caused by earthquake loading.
Finally, the proposed models were compared with the existing relationship for the estimation of earthquakeinduced crest settlement of embankment dams.

\section{Case histories}

In the present study, comprehensive data of crest settlements of embankment dams subjected to past earthquakes in different parts of the world were collected. The results included homogeneous and nonhomogeneous embankment dams, concrete-faced dams, rockfill dams, and also some natural soil slopes. The collected cases were those for which thorough information about their behavior and also earthquake characteristics were recorded and available. The database includes a total of 151 real-world cases. The statistical specifications of the parameters of yield acceleration $\left(a_{y}\right)$, maximum horizontal acceleration of the earthquake $\left(a_{\max }\right)$, yield acceleration ratio $\left(a_{y} / a_{\max }\right)$, fundamental period of the embankment dam $\left(T_{d}\right)$, predominant period of the earthquake $\left(T_{p}\right)$, fundamental period ratio $\left(T_{d} / T_{p}\right)$, earthquake magnitude $\left(M_{w}\right)$, embankment height $(H)$, crest settlement of the embankment dam $(S)$, and the crest settlement ratio of embankment dam $(S / H)$ are presented in Table 1 . The yield acceleration was estimated by pseudo-static slope stability analysis [16]. The values of $a_{\max }$ and $T_{p}$ were determined from acceleration records from instruments at the dams or embankments sites. The fundamental period of the embankment dam $\left(T_{d}\right)$ was obtained from [41]. In this study, the yield acceleration ratio $\left(a_{y} / a_{\max }\right)$, fundamental period ratio $\left(T_{d} / T_{p}\right)$, and earthquake magnitude $\left(M_{w}\right)$ were considered as the most important parameters that affect the crest settlement of embankment dams. The detailed characteristics of the database are presented in Table A.1.

\section{SVR framework}

The Support Vector Machine (SVM) has been derived from the machine learning theory, as proposed by Vapnik [42]. The SVM was initially used to classify data; however, its algorithm was then developed further to solve regression problems and predict time series [43]. 
Assume an experimental dataset $\left\{\left(x_{1}, y_{1}\right), \ldots\right.$, $\left.\left(x_{n}, y_{n}\right)\right\}$ in an $n$-dimensional space, where $x$ and $y$ denote the input values $\left(x \in R^{n}\right)$ and output values $(y \in R)$, respectively. In the SVM-based regression model, the objective is to approximate $y_{i}$ values using function $f(x)$, such that the error is minimized [43]:

$$
f(x)=w^{T} x+b,
$$

where $b$ and $w$ represent bias and weight vector, respectively. In order to find the values of $w$ and $b$, an empirical risk is defined as follows:

$$
R=\frac{1}{2}\|w\|^{2}+\frac{C}{n} \sum_{i=1}^{n}\left|y_{i}-f\left(x_{i}\right)\right|_{\varepsilon}
$$

where $C>0$ controls the error of deviation higher than $\varepsilon$, and $\frac{1}{2}|| w \|^{2}$ is the complexity index of the objective function. In fact, the lower the value of $\left.\frac{1}{2}\|w\|\right|^{2}$, the simpler the objective function [44].

In the SVR, the ultimate goal is to minimize empirical risk. Therefore, a $\varepsilon$-insensitive loss function was proposed by Vapnik [45]:

$$
\left|y_{i}-f\left(x_{i}\right)\right|_{\varepsilon}= \begin{cases}0, & \left|y_{i}-f\left(x_{i}\right)\right| \leq \varepsilon \\ \left|y_{i}-f\left(x_{i}\right)\right|-\varepsilon, & \text { otherwise }\end{cases}
$$

Based on Figure 1, Eq. (3) can be explained as a region with radius, $\varepsilon$, around the hypothetical regression function, such that the upper and lower limits of this region are referred to as the support vector. As long as the data are located inside the limits of the support vectors, the $\varepsilon$-insensitive function remains equal to zero. Any data located outside this region will be penalized with respect to its distance from the support vector [43]. This distance is referred to as violation and denoted by $\lambda$. In the 2-dimensional space, one can write:

$$
\begin{aligned}
& \text { Minimize } \frac{1}{2}\|w\|^{2}+C \sum_{i=1}^{n}\left(\lambda_{i}^{+}, \lambda_{i}^{-}\right), \\
& \text {Subject : }\left\{\begin{array}{l}
\left(w \cdot x_{i}+b\right)-y_{i} \leq \varepsilon+\lambda_{i}^{+} \\
y_{i}-\left(w \cdot x_{i}+b\right) \leq \varepsilon+\lambda_{i}^{-} \\
\lambda_{i}^{+}, \lambda_{i}^{-} \geq 0
\end{array}\right.
\end{aligned}
$$

This problem in a dual space is expressed as follows:

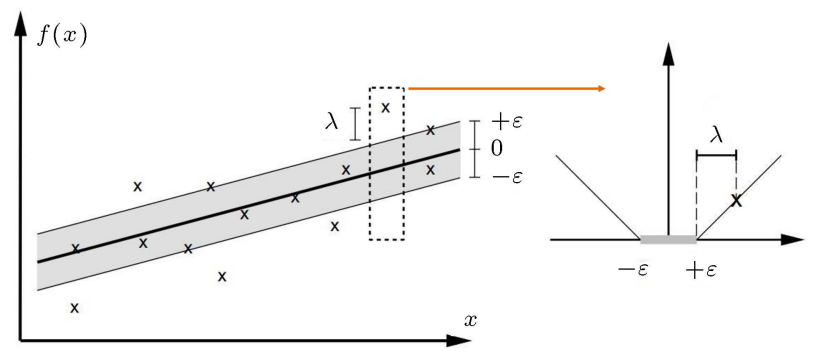

Figure 1. $\varepsilon$-insensitive loss function for the Support Vector Regression (SVR)-based model.
Table 2. Values of the parameters of the proposed Support Vector Regression (SVR)-based model.

\begin{tabular}{cc}
\hline Parameter & Optimal value \\
\hline$\sigma$ & 0.35 \\
$\mathrm{C}$ & 1000 \\
$\varepsilon$ & 0.005 \\
\hline
\end{tabular}

$$
f(x)=\sum_{i=1}^{n_{s v}}\left(\beta_{i}-\beta_{i}^{*}\right) K\left(x_{i}, x\right)+b,
$$

where $n_{s v}$ is the number of support vectors, $\beta_{i}$ and $\beta_{i}^{*}$ are the Lagrange coefficients, and $K\left(x_{i}, x\right)$ is the kernel function [46]. In nonlinear spaces, the Radial Basis Function (RBF) [47] offers more acceptable results than other functions [48]. Therefore, in this study, the RBF kernel is used as follows:

$$
K\left(x_{i}, x_{j}\right)=\exp \left(-\frac{\left\|x_{i}-x_{j}\right\|^{2}}{2 \rho^{2}}\right), \rho \in R .
$$

The training procedure used 75 percent of the collected dataset, and the remaining 25 percent was used to validate the performance of the SVR-based model. The training and validation data were selected such that the statistical parameters of both categories were as close as possible. Numerous runs were carried out with various initial settings, and the performance of the developed SVR-based models was analyzed for each run. Consequently, the optimal parameters employed in the proposed model (Table 2) were selected.

In order to assess the performance of the developed models, the coefficient of determination, $R^{2}$, Mean Absolute Error, MAE, and Root Mean Squared Error, RMSE, [19] between the measured and predicted $S / H$ were checked.

\section{Results}

\subsection{MLR-based model}

In this study, using gathered data (Table 1), an MLR based model was developed using SPSS program for the earthquake-induced crest settlement of embankment dams as Eq. (8):

$$
\begin{aligned}
\ln \left(\frac{S}{H}\right)= & -1.471 \ln \left(\frac{a_{y}}{a_{\max }}\right)-1.886 \ln \left(\frac{T_{d}}{T_{p}}\right) \\
& -0.849 M_{w},
\end{aligned}
$$

where the earthquake-induced crest settlement ratio of embankment dam $(S / H)$ was developed on the basis of yield acceleration ratio $\left(a_{y} / a_{\max }\right)$, fundamental period ratio $\left(T_{d} / T_{p}\right)$, and earthquake magnitude $\left(M_{w}\right)$, respectively.

The comparison between the measured and predicted crest settlement values using the MLR model 
(Eq. (8)) is demonstrated in Figure 2. The values of $R^{2}$, MAE, and RMSE for the MLR-based model, developed to assess the seismic crest settlement of embankment dams, were $0.898,1.746$, and 2.305 , respectively.

\subsection{SVR-based model}

In the present study, many SVR based models were investigated by applying different initial parameter values. Ultimately, based on the calculated error parameters, the model with the highest accuracy was selected to predict the crest settlement of embankment dams subjected to earthquake loads.

The accuracy of the proposed SVR-based model in the training and validation stages is respectively compared in Figures 3 and 4 by comparing the measured values and the predicted values of crest settlement ratio $(S / H)$ of embankment dams under earthquake loading. The values of $R^{2}$, MAE, and RMSE for the proposed SVR-based model in the

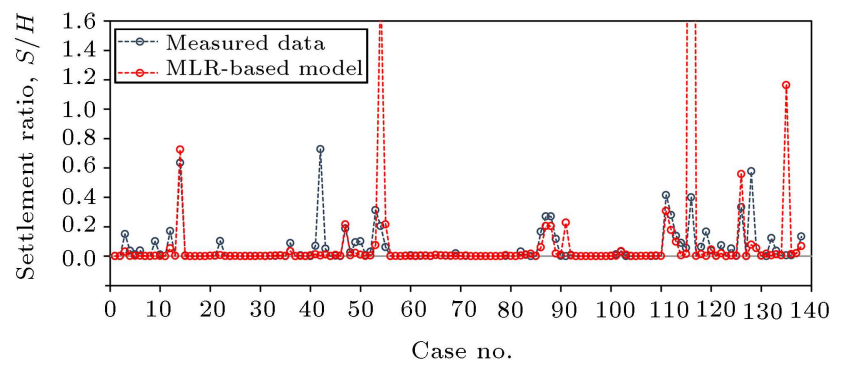

Figure 2. Comparison of measured and Multiple Linear Regression (MLR)-based predicted values of $S / H$.

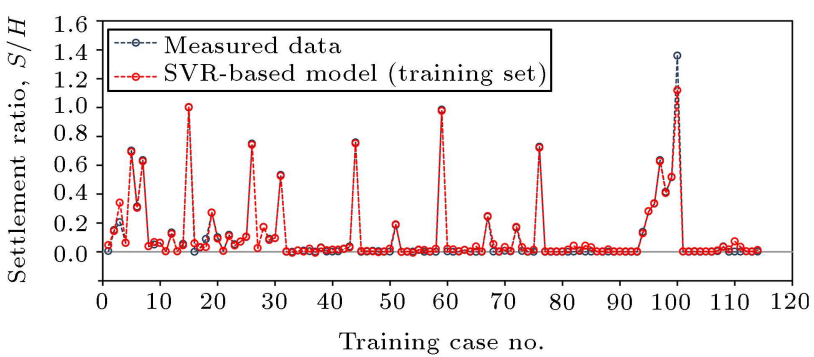

Figure 3. Comparison of measured and Support Vector Regression (SVR)-based predicted values of $S / H$ for training stage.

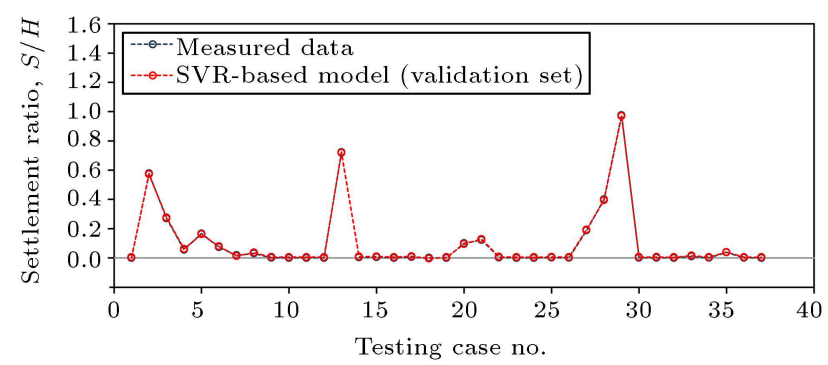

Figure 4. Comparison of measured and Support Vector Regression (SVR)-based predicted values of $S / H$ for validation stage. training and validation stages were obtained as 0.987 , 0.013 , and 0.03 (Figure 3) and 0.999, 0.005, and 0.005, respectively (Figure 4). The results indicate the acceptable accuracy of the SVR-based model in estimating the crest settlement of embankment dams under earthquake loadings.

\section{Sensitivity analysis}

Sensitivity analysis was carried out to investigate 1) the effect of each influential parameter on the crest settlement of embankment dams subjected to seismic vibrations and 2) the consistency of the proposed model obtained using soft computations with the real case histories under different conditions. To this end, the effect of changes in each of the input parameters (i.e., $M_{w}, a_{y} / a_{\max }$, and $\left.T_{d} / T_{p}\right)$ on the seismic settlement of the crest of embankment dams was investigated, such that the other parameters were fixed at the average value in the dataset (Table 1 ).

The measured values of crest settlement ratio $(S / H)$ of embankment dams under past earthquakes and the MLR- and SVR-based predicted values with respect to yield acceleration ratio $\left(a_{y} / a_{\max }\right)$, fundamental period ratio $\left(T_{d} / T_{p}\right)$, and earthquake magnitude $\left(M_{w}\right)$ are illustrated in Figures 5,6 , and 7 , respectively. Their best fitted curves are also presented in the figures for comparison. As shown in Figures 5 and 6 , the crest settlement ratio of the embankment dams decreases by increasing $a_{y} / a_{\max }$ and $T_{d} / T_{p}$. An increase in the earthquake magnitude also increased the $S / H$ value (Figure 7 ). Generally, based on the comparison of the variations of $S / H$ ratio and the real results recorded in the past earthquakes, it can be concluded that the proposed MLR- and SVR-based models have appropriate performance.

\section{Comparison with Swaisgood's relationship [49]}

The relationship proposed by Swaisgood [49] is used for a preliminary assessment of the crest settlement of embankment dams under earthquake shaking. Based on the collected information from 69 different dams, Swaisgood [49] proposed Eq. (9) to estimate the earthquake-induced crest settlement ratio of embankment dams:

$$
\frac{S}{H}=0.01 \exp \left(6.07 a_{\max }+0.57 M_{w}-8\right) \text {. }
$$

In Eq. (9), for the calculation of $H$, the thickness of the alluvial layer is also taken into account. However, in many cases where information on the thickness of the alluvial layer is not available, its value is set to the height of the dam [49]. In this study, the thickness of the alluvial layer is also considered in Swaisgood's 


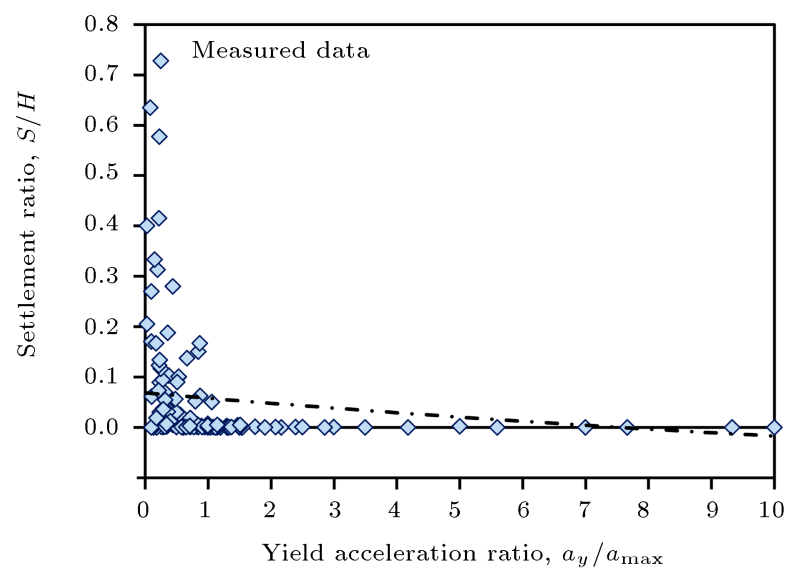

(a)

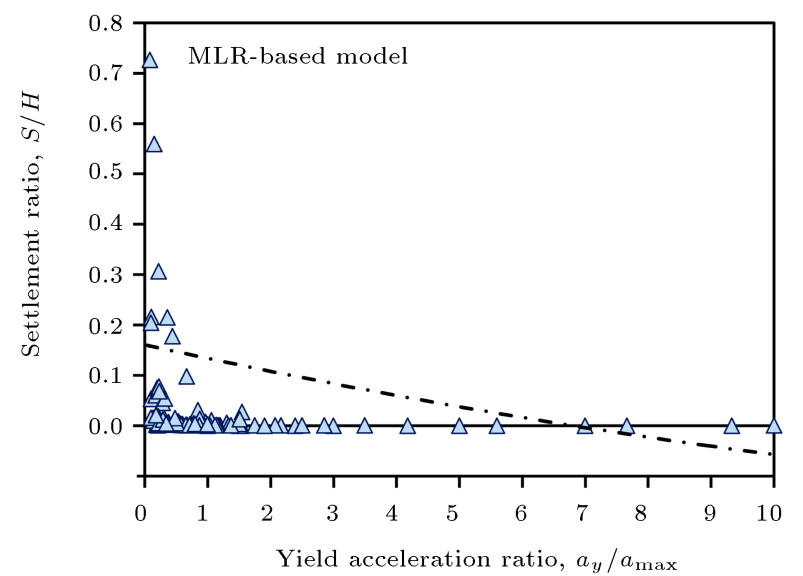

(b)

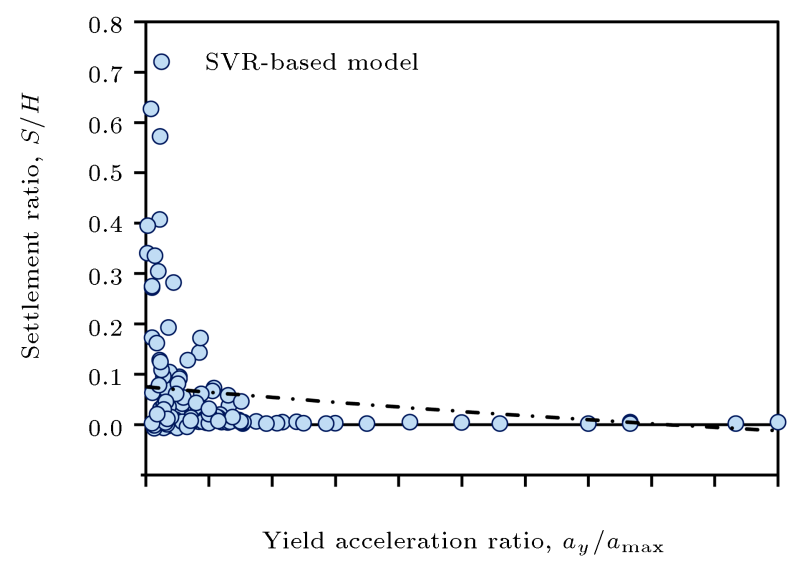

(c)

Figure 5. Variations of settlement ratio versus yield acceleration ratio for (a) Measured data, (b) predicted by the Multiple Linear Regression (MLR)-based model, and (c) predicted by the Support Vector Regression (SVR)-based model.

relationship [49] for the cases where the detailed information about deposits below embankment dam was available.

The comparison between the proposed MLRand SVR-based models with the Swaisgood's relation-

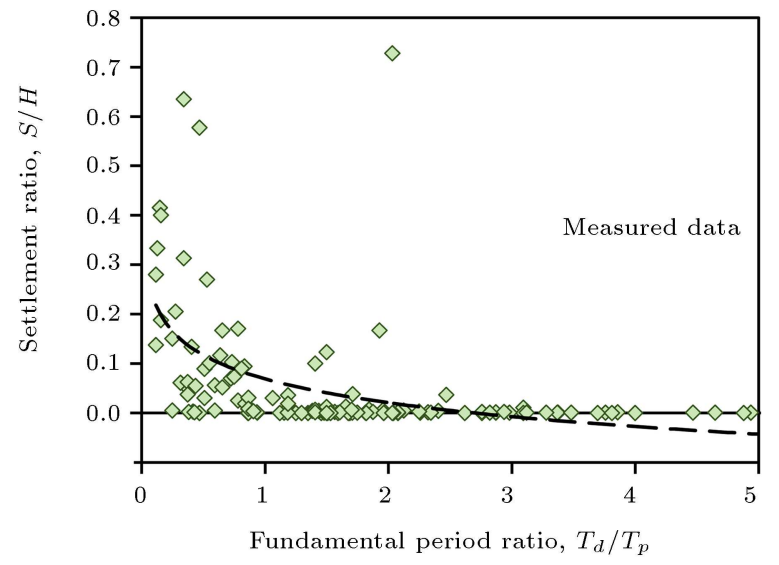

(a)

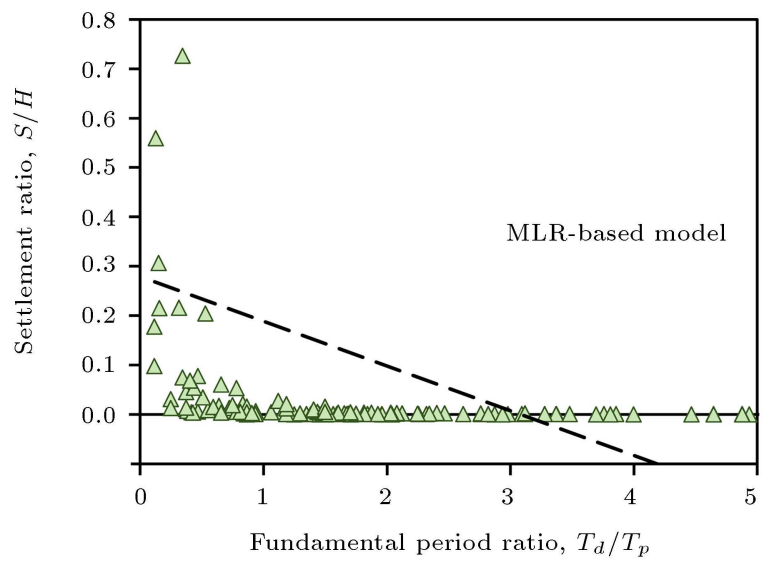

(b)

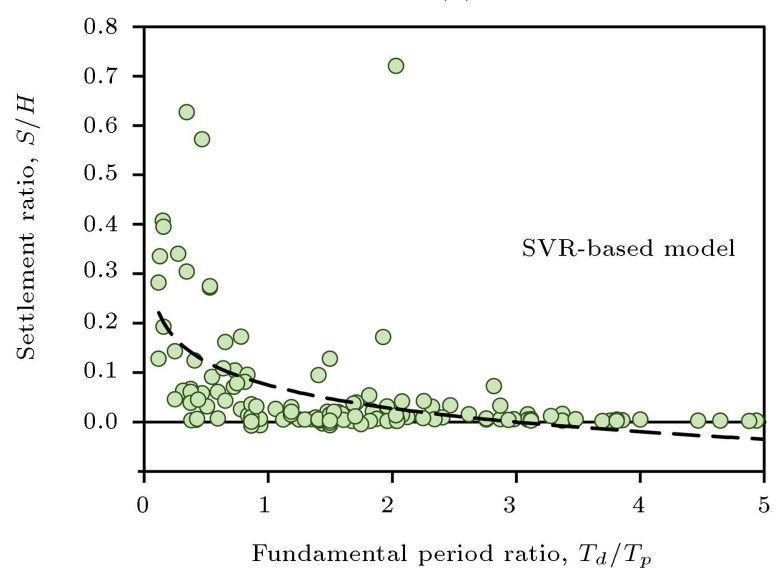

(c)

Figure 6. Variations of settlement ratio versus fundamental period ratio for (a) measured data, (b) predicted by the Multiple Linear Regression (MLR)-based model, and (c) predicted by the Support Vector Regression (SVR)-based model.

ship [49] is demonstrated in Figure 8. As depicted in Figure 8, the relationship proposed by Swaisgood [49] underestimates the earthquake-induced crest settlement ratio $(S / H)$ of embankment dams compared to the real values. Moreover, the accuracy of the relationship (Eq. (9)) decreased by increasing the $S / H$ 


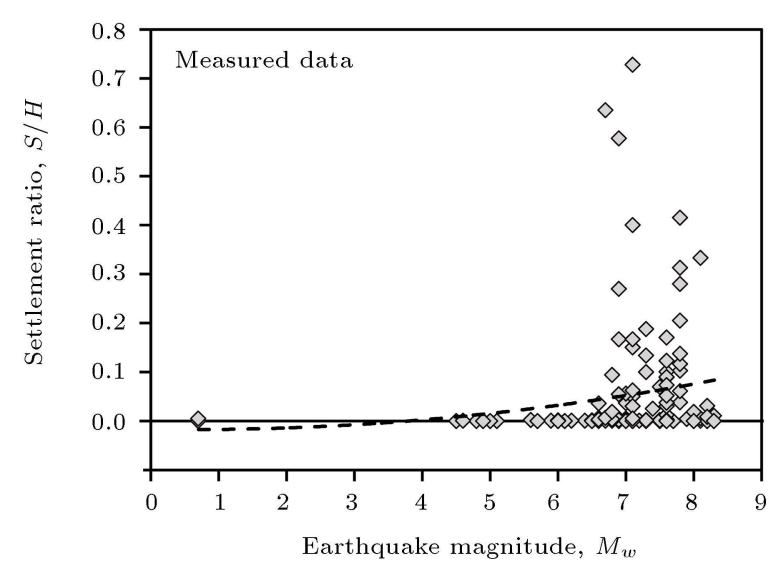

(a)

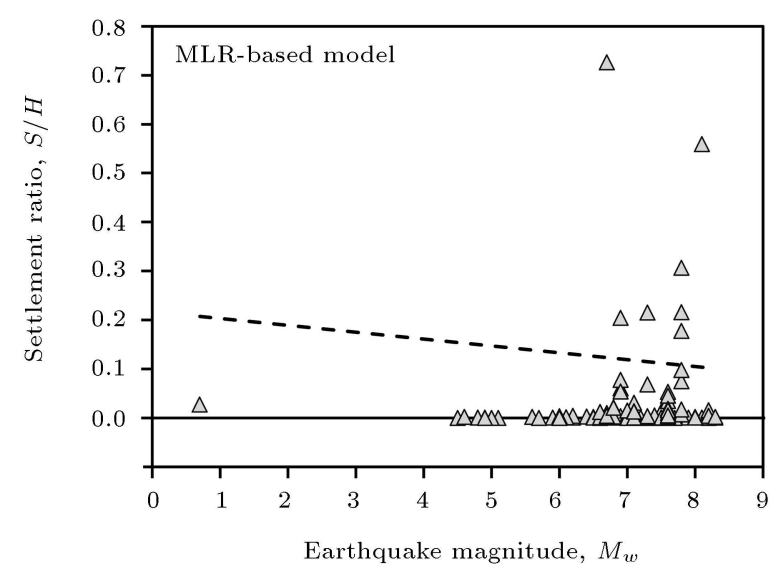

(b)

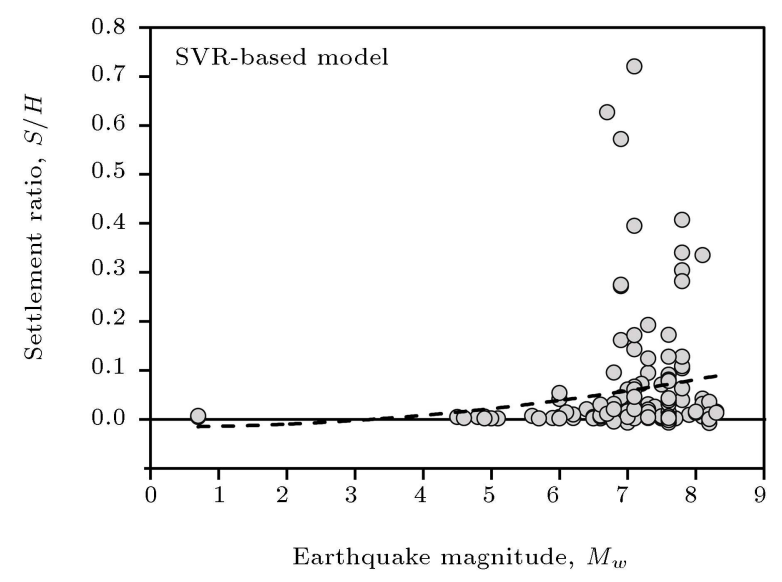

(c)

Figure 7. Variations of settlement ratio versus earthquake magnitude for (a) measured data, (b) predicted by Multiple Linear Regression (MLR)-based model, and (c) predicted by Support Vector Regression (SVR)-based model.

ratio (Figure 8). Important parameters such as yield acceleration $\left(a_{y}\right)$ and fundamental period of dam $\left(T_{d}\right)$, as the key characteristics in the earthquake-induced behavior of embankment dams, are considered to be one of the main reasons of the low accuracy of Eq. (9).

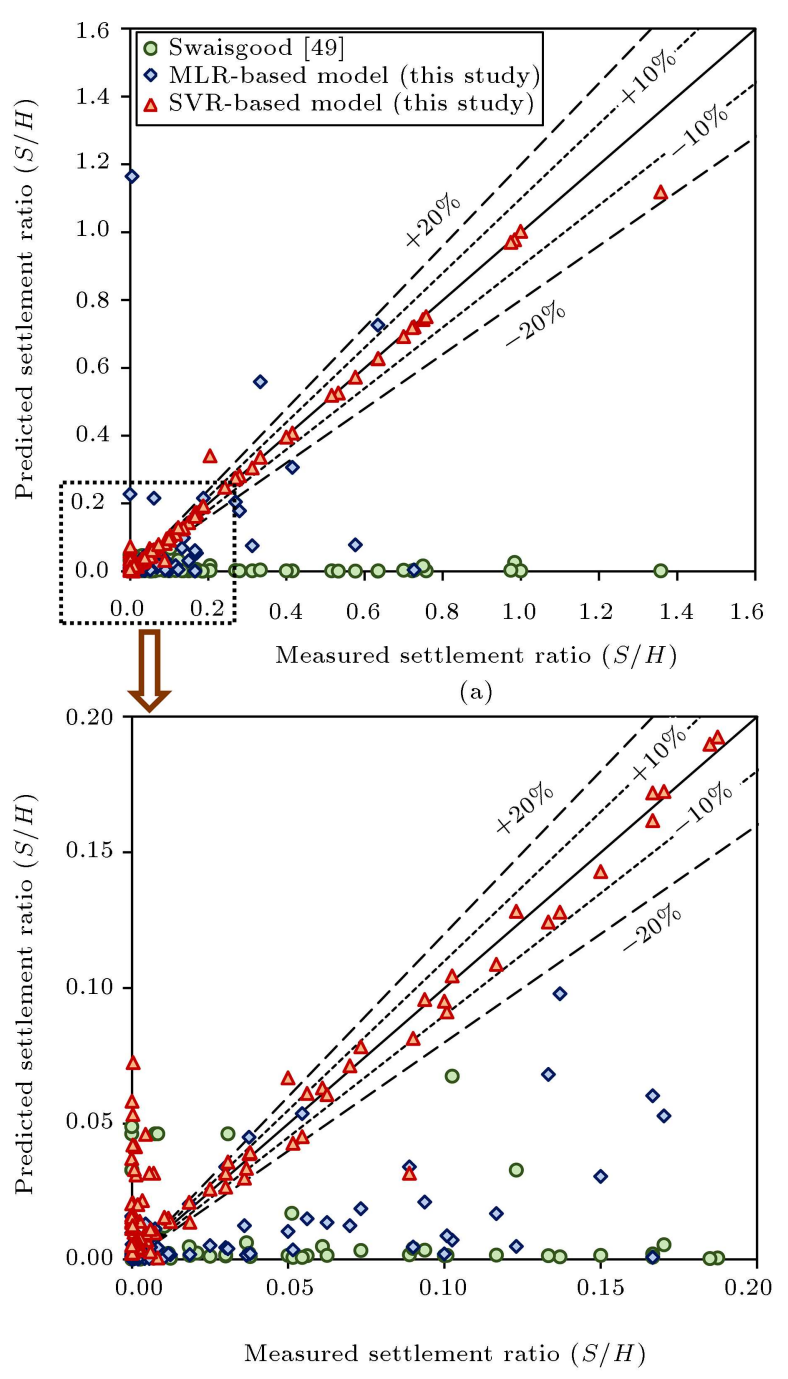

(b)

Figure 8. Comparison of Multiple Linear Regression (MLR)- and Support Vector Regression (SVR)-based models with relationship proposed by Swaisgood [49]: (a) General view, and (b) zoomed view.

The comparison presented in Figure 8 indicates the appropriate accuracy of the proposed regressive models in predicting the seismic crest settlement of embankment dams. The correlation coefficient, $R^{2}$, MAE, and RMSE for the proposed models and available relationship are presented in Table 3. The statistical indexes (Table 3) indicate that the SVRbased model enjoys higher accuracy in comparison to the MLR-based model in estimating the earthquakeinduced crest settlement ratio $(S / H)$ of embankment dams.

The complexity of the geotechnical earthquake engineering problems makes the available models incapable of accurately reflecting all the factors affecting the earthquake-induced settlement of embankment dams. However, note that the available models are still commonly used in the initial designs. Hence, 
Table 3. Statistical parameters of various models.

\begin{tabular}{ccccc}
\hline Model & Dataset & $\boldsymbol{R}^{\mathbf{2}}$ & MAE & RMSE \\
\hline MLR & All data & 0.898 & 1.746 & 2.305 \\
SVR & Training set & 0.987 & 0.013 & 0.030 \\
& Validation set & 0.999 & 0.005 & 0.005 \\
& All data & 0.989 & 0.011 & 0.028 \\
Swaisgood [49] & All data & 0.012 & 0.109 & 0.260 \\
\hline
\end{tabular}

employing computational methods can be a worthy step in reducing the uncertainties in estimating the deformation of embankment dams under earthquake vibrations.

\section{Summary and conclusion}

Evaluating behavior of dams under earthquake vibrations is of great significance. Therefore, the present study attempted to predict the earthquakeinduced crest settlement of embankment dams. To this end, wide-ranging data cases of the real earthquakeinduced deformations in different types of embankment dams including 151 cases were collected and analyzed. The most important parameters affecting the crest settlement in embankment dams induced by earthquake shaking were determined. The parameters of earthquake magnitude $\left(M_{w}\right)$, maximum horizontal acceleration of the earthquake $\left(a_{\max }\right)$, predominant period of the earthquake $\left(T_{P}\right)$, fundamental period of embankment dam $\left(T_{d}\right)$, and yield acceleration of embankment dam $\left(a_{y}\right)$ were considered as the most important factors that control earthquake-induced deformations in embankment dams.

The Support Vector Regression (SVR) and Multiple Linear Regression (MLR) methods were used to develop the models for the assessment of seismic settlement of embankment dams, $S$. The yield acceleration ratio $\left(a_{y} / a_{\max }\right)$, fundamental period ratio $\left(T_{d} / T_{p}\right)$, and earthquake magnitude $\left(M_{w}\right)$ were considered as the input parameters, while the crest settlement ratio of the dam $(S / H)$ was considered as the output parameter. Assessing the accuracy of the proposed regressive models indicates that although both the SVR-based model $\left(R^{2}=0.989, \mathrm{MAE}=0.011\right.$, and $\mathrm{RMSE}=$ $0.028)$ and the MLR-based model $\left(R^{2}=0.898\right.$, MAE $=$ 1.746 , and RMSE $=2.305$ ) offered acceptable accuracy, the SVR-based model had higher accuracy. Then, sensitivity analysis was conducted to assess the behavior of the developed models under different conditions and the effect of each of the input parameters on the crest settlement ratio of the embankment dams $(S / H)$. Finally, the performance of the proposed models was compared to the available relationship for the assessment of crest settlement of embankment dams subjected to earthquake loading. Certainly, recording more results on the real deformations of the embankment dams under real earthquake vibrations can lead to the development of more accurate computational models.

\section{Nomenclature}

$\begin{array}{ll}a_{y} & \text { Yield acceleration of dam } \\ a_{\text {max }} & \text { Maximum horizontal earthquake } \\ & \text { acceleration } \\ T_{d} & \text { Fundamental period of dam body } \\ T_{p} & \text { Predominant period of earthquake } \\ M_{w} & \text { Earthquake magnitude } \\ S & \text { Crest settlement of embankment dam } \\ H & \text { Embankment height } \\ S V M & \text { Support Vector Machine } \\ \text { SVR } & \text { Support Vector Regression } \\ \text { RBF } & \text { Radial Basis Function } \\ \text { MLR } & \text { Multiple Linear Regression } \\ b & \text { Bias } \\ w & \text { Weight vector } \\ R & \text { Empirical risk } \\ \lambda & \text { Distance from the support vector } \\ n & \text { Number of support vectors } \\ \beta_{i} & \text { Lagrange coefficient } \\ K & \text { Kernel function } \\ R & \text { Coefficient of determination } \\ \text { MAE } & \text { Mean Absolute Error } \\ \text { RMSE } & \text { Root Mean Squared Error } \\ & \end{array}$

\section{References}

1. Meehan, C.L. and Vahedifard, F. "Evaluation of simplified methods for predicting earthquake-induced slope displacements in earth dams and embankments", Engineering Geology, 152(1), pp. 180-193 (2013).

2. Newmark, N.M. "Effects of earthquakes on dams and embankments", Geotechnique, 15(2), pp. 139-160 (1965).

3. Garini, E., Gazetas, G., and Anastasopoulos, I. "Asymmetric 'Newmark' sliding caused by motions containing severe 'directivity' and 'fling' pulses", Geotechnique, 61(9), pp. 733-756 (2011). 
4. Makdisi, F.I. and Seed, H.B. "Simplified procedure for estimating dam and embankment earthquake-induced deformations", Journal of Geotechnical Engineering, 104(7), pp. 849-867 (1978).

5. Sarma, S.K. "Seismic stability of earth dams and embankments", Geotechnique, 25(4), pp. 743-761 (1975).

6. Bray, J.D., Macedo, J., and Travasarou, T. "Simplified procedure for estimating seismic slope displacements for subduction zone earthquakes", Journal of Geotechnical and Geoenvironmental Engineering, 144(3), 04017124 (2017).

7. Hynes-Griffin, M.E. and Franklin, A.G. "Rationalizing the seismic coefficient method", Misc. Paper GL-84-13. U.S. Army Waterway Experiment Station, Vicksburg, Mississippi (1984).

8. Kramer, S.L. and Smith, M.W. "Modified Newmark model for seismic displacements of compliant slopes", Journal of Geotechnical and Geoenvironmental Engineering, 123(7), pp. 635-644 (1997).

9. Bray, J.D. and Rathje, E.M. "Earthquake-induced displacements of solid-waste landfills", Journal of Geotechnical and Geoenvironmental Engineering, 124(3), pp. 242-253 (1998).

10. Rathje, E.M. and Bray, J.D. "Nonlinear coupled seismic sliding analysis of earth structures", Journal of Geotechnical and Geoenvironmental Engineering, 126(11), pp. 1002-1014 (2000).

11. Bray, J.D. and Travasarou, T. "Simplified procedure for estimating earthquake-induced deviatoric slope displacements", Journal of Geotechnical and Geoenvironmental Engineering, 133(4), pp. 381-392 (2007).

12. Jibson, R.W. "Regression models for estimating coseismic landslide displacement", Engineering Geology, 91(2), pp. 209-218 (2007).

13. Ebrahimian, B. "Numerical analysis of nonlinear dynamic behavior of earth dams", Frontiers of Architecture and Civil Engineering in China, 5(1), pp. 24-40 (2011).

14. Park, D.S. and Kim, N.R. "Safety evaluation of cored rockfill dams under high seismicity using dynamic centrifuge modeling", Soil Dynamics and Earthquake Engineering, 97, pp. 345-363 (2017).

15. Kim, M.K., Lee, S.H., Choo, Y.W., and Kim, D.S. "Seismic behaviors of earth-core and concrete-faced rock-fill dams by dynamic centrifuge tests", Soil Dynamics and Earthquake Engineering, 31(11), pp. 15791593 (2011).

16. Singh, R., Roy, D., and Das, D. "A correlation for permanent earthquake-induced deformation of earth embankments", Engineering Geology, 90(3), pp. 174185 (2007).

17. Singh, R. and Roy. D. "Estimation of earthquakeinduced crest settlements of embankments", American Journal of Engineering and Applied Sciences, 2(3), pp. 515-525 (2009).
18. Jafarian, Y., Haddad, A., and Javdanian, H. "Predictive model for normalized shear modulus of cohesive soils", Acta Geodynamica et Geomaterialia, 11(1), pp. 89-100 (2014).

19. Javdanian, H., Jafarian, Y., and Haddad, A. "Predicting damping ratio of fine-grained soils using soft computing methodology", Arabian Journal of Geosciences, 8(6), pp. 3959-3969 (2015).

20. Javdanian, H., Haddad, A., and Jafarian, A. "Evaluation of dynamic behavior of fine-grained soils using group method of data handling", Transportation Infrastructure Engineering, 1(3), pp. 77-92 (2015).

21. Javdanian, H. "Assessment of shear stiffness ratio of cohesionless soils using neural modeling", Modeling Earth Systems and Environment, 3(3), pp. 1045-1053 (2017).

22. Javdanian, H. "The Effect of geopolymerization on the unconfined compressive strength of stabilized finegrained soils", International Journal of EngineeringTransactions B: Applications, 30(11), pp. 1673-1680 (2017).

23. Javdanian, H. and Lee, S. "Evaluating unconfined compressive strength of cohesive soils stabilized with geopolymer: a computational intelligence approach", Engineering with Computers, 35(1), pp. 191-199 (2019).

24. Javdanian, H., Haddad, A., and Mehrzad, B. "Experimental and numerical investigation of the bearing capacity of adjacent footings on reinforced soil", Electronic Journal of Geotechnical Engineering, 17(R), pp. 2597-2617 (2012).

25. Javdanian, H. "Evaluation of soil liquefaction potential using energy approach: experimental and statistical investigation", Bulletin of Engineering Geology and the Environment (2017). DOI: 10.1007/s10064-017-1201-6

26. Yaghmaei-Sabegh, S. "Earthquake ground-motion duration estimation by using of general regression neural network", Scientia Iranica, 25(5), pp. 2425-2439 (2017). DOI: $10.24200 /$ sci.2017.4217

27. Najafzadeh, M. and Barani, G.A. "Comparison of group method of data handling based genetic programming and back propagation systems to predict scour depth around bridge piers", Scientia Iranica, 18(6), pp. 1207-1213 (2011).

28. Najafzadeh, M., Barani, G.A., and Hessami-Kermani, M.R. "Group method of data handling to predict scour depth around vertical piles under regular waves", Scientia Iranica, 20(3), pp. 406-413 (2013).

29. Najafzadeh, M. and Lim, S.Y. "Application of improved neuro-fuzzy GMDH to predict scour depth at sluice gates", Earth Science Informatics, 8(1), pp. 187196 (2015).

30. Najafzadeh, M., Shiri, J., and Rezaie-Balf, M. "New expression-based models to estimate scour depth at clear water conditions in rectangular channels", $M a$ rine Georesources \& Geotechnology, 36(2), pp. 227235 (2018). 
31. Najafzadeh, M., Tafarojnoruz, A., and Lim, S.Y. "Prediction of local scour depth downstream of sluice gates using data-driven models", ISH Journal of Hydraulic Engineering, 23(2), pp. 195-202 (2017).

32. Shooshpasha, I., Amiri, I., and MolaAbasi, H. "An investigation of friction angle correlation with geotechnical properties for granular soils using GMDH type neural networks", Scientia Iranica, 22(1), pp. 157-164 (2015).

33. Habibagahi, G. and Taherian, M. "Prediction of collapse potential for compacted soils using artificial neural networks", Scientia Iranica, 11(1), pp. 1-20 (2004).

34. Kovacevic, M., Bajat, B., and Gajic, B. "Soil type classification and estimation of soil properties using support vector machines", Geoderma, 154(3), pp. 340347 (2010).

35. Pasolli, L., Notarnicola, C., and Bruzzone, L. "Estimating soil moisture with the support vector regression technique", IEEE Geoscience and Remote Sensing Letters, 8(6), pp. 1080-1084 (2011).

36. Lee, D., Kim, G., and Lee, K.E. "Soil moisture prediction using a support vector regression", Journal of the Korean Data and Information Science Society, 24(2), pp. 401-408 (2013).

37. Elbisy, M.S. "Support vector machine and regression analysis to predict the field hydraulic conductivity of sandy soil", KSCE Journal of Civil Engineering, 19(7), pp. 2307-2316 (2015).

38. Soltani, N. and Bagheripour, M.H. "Seismic wave scatter study in valleys using coupled 2D finite element approach and absorbing boundaries", Scientia Iranica, 24(1), pp. 110-120 (2017).

39. Jafarian, Y., Javdanian, H., and Haddad, A. "Straindependent dynamic properties of Bushehr siliceouscarbonate sand: Experimental and comparative study", Soil Dynamics and Earthquake Engineering, 107, pp. 339-349 (2018).

40. Jafarian, Y., Javdanian, H., and Haddad, A. "Dynamic properties of calcareous and siliceous sands under isotropic and anisotropic stress conditions", Soils and Foundations, 58(1), pp. 172-184 (2018).

41. Gazetas, P. and Dakoulas, P. "Seismic analysis and design of rockfill dams", Soil Dynamics and Earthquake Engineering, 11, pp. 27-61 (1991).

42. Vapnik, V. "An overview of statistical learning theory", IEEE Transactions on Neural Networks, 10(5), pp. 988-999 (1999).

43. Smola, A.J. and Schölkopf, B. "A tutorial on support vector regression", Statistics and Computing, 14(3), pp. 199-222 (2004).

44. Ustun, B., Melssen. W.J., Oudenhuijzen, M., and Buydens, L.M.C. "Determination of optimal support vector regression parameters by genetic algorithms and simplex optimization", Analytica Chemica Acta, 544, pp. 292-305 (2005).

45. Vapnik, V., The Nature of Statistical Learning Theory, Springer Science \& Business Media (2013).

46. Cherkassky, V. and Ma, Y. "Practical selection of SVM parameters and noise estimation for SVM regression", Neural Networks, 17(1), pp. 113-126 (2004).

47. Zarif Sanayei, H.R., Talebbeydokhti, N., and Moradkhani, H. "3D estimation of metal elements in sediments of the Caspian Sea with moving least square and radial basis function interpolation methods", Scientia Iranica, 22(5), pp. 1661-1673 (2015).

48. Fattahi, H. "Prediction of earthquake induced displacements of slopes using hybrid support vector regression with particle swarm optimization", Int $J$ Optim Civil Eng, 5(3), pp. 267-282 (2015).

49. Swaisgood, J.R. "Embankment dam deformations caused by earthquakes", In Pacific Conference on Earthquake Engineering, Paper No. 14 (2003).

\section{Appendix A}

Table A.1 presents 151 case histories that were used to develop SVR based model.

Table A.1. Summary of datasets used to develop Support Vector Regression (SVR)-based models.

\begin{tabular}{cccccccccc}
\hline No. & $\boldsymbol{M}_{\boldsymbol{w}}$ & $\boldsymbol{a}_{\boldsymbol{y}} / \boldsymbol{a}_{\max }$ & $\boldsymbol{T}_{\boldsymbol{d}} / \boldsymbol{T}_{\boldsymbol{p}}$ & $\boldsymbol{S} / \boldsymbol{H}$ & $\mathbf{N o .}$ & $\boldsymbol{M}_{\boldsymbol{w}}$ & $\boldsymbol{a}_{\boldsymbol{y}} / \boldsymbol{a}_{\max }$ & $\boldsymbol{T}_{\boldsymbol{d}} / \boldsymbol{T}_{\boldsymbol{p}}$ & $\boldsymbol{S} / \boldsymbol{H}$ \\
\hline 1 & 7.1 & 1.52 & 0.25 & 0.004 & 11 & 7.6 & 0.96 & 0.382 & 0.0017 \\
2 & 7.1 & 0.85 & 0.25 & 0.15 & 12 & 7.3 & 0.23 & 0.406 & 0.13 \\
3 & 7.8 & 0.029 & 0.275 & 0.205 & 13 & 7.6 & 1.30 & 0.418 & 0.003 \\
4 & 7.8 & 0.108 & 0.315 & 0.061 & 14 & 6.9 & 0.318 & 0.437 & 0.05 \\
5 & 7.8 & 0 & 0.325 & 0.7 & 15 & 7.9 & 0 & 0.437 & 1 \\
6 & 7.8 & 0.20 & 0.343 & 0.312 & 16 & 7 & 1.31 & 0.468 & 0.00005 \\
7 & 6.7 & 0.083 & 0.343 & 0.634 & 17 & 7.6 & 0.23 & 0.509 & 0.031 \\
8 & 7.6 & 0.285 & 0.375 & 0.037 & 18 & 7.6 & 0.23 & 0.509 & 0.08 \\
9 & 7.1 & 1.06 & 0.375 & 0.05 & 19 & 6.9 & 0.10 & 0.531 & 0.27 \\
10 & 7.1 & 0.878 & 0.375 & 0.062 & 20 & 7.6 & 0.53 & 0.55 & 0.1008 \\
\hline
\end{tabular}


Table A.1. Summary of datasets used to develop Support Vector Regression (SVR)-based models (continued).

\begin{tabular}{|c|c|c|c|c|c|c|c|c|c|}
\hline No. & $M_{w}$ & $a_{y} / a_{\max }$ & $T_{d} / T_{p}$ & $S / H$ & No. & $M_{w}$ & $a_{y} / a_{\max }$ & $T_{d} / T_{p}$ & $S / H$ \\
\hline 21 & 0.7 & 1.15 & 0.598 & 0.005 & 68 & 6 & 0.6 & 1.8 & 0.00034 \\
\hline 22 & 7.8 & 0.25 & 0.63 & 0.117 & 69 & 6.5 & 2.85 & 1.82 & 0.00002 \\
\hline 23 & 7.6 & 0.80 & 0.657 & 0.052 & 70 & 6.8 & 1 & 1.84 & 0.00698 \\
\hline 24 & 7.5 & 0.31 & 0.72 & 0.07 & 71 & 6.9 & 0.34 & 1.87 & 0.0019 \\
\hline 25 & 7.8 & 0.378 & 0.73 & 0.10 & 72 & 7.1 & 0.86 & 1.92 & 0.167 \\
\hline 26 & 6.8 & 0 & 0.75 & 0.75 & 73 & 8.1 & 0.83 & 1.95 & 0.0056 \\
\hline 27 & 7.4 & 0.56 & 0.78 & 0.02 & 74 & 5 & 50 & 1.96 & 0.00002 \\
\hline 28 & 7.6 & 0.10 & 0.78 & 0.17 & 75 & 8.3 & 0.188 & 2.03 & 0.00004 \\
\hline 29 & 7.6 & 0.51 & 0.81 & 0.09 & 76 & 7.1 & 0.25 & 2.03 & 0.728 \\
\hline 30 & 6.8 & 0.28 & 0.83 & 0.094 & 77 & 6.6 & 23 & 2.03 & 0.00001 \\
\hline 31 & 5.3 & 0 & 0.84 & 0.53 & 78 & 5 & 20 & 2.04 & 0.00002 \\
\hline 32 & 7.7 & 9.33 & 0.86 & 0.00001 & 79 & 4.9 & 28.58 & 2.04 & 0.00002 \\
\hline 33 & 8.2 & 0.138 & 0.86 & 0.00003 & 80 & 4.9 & 40 & 2.04 & 0.00002 \\
\hline 34 & 8.2 & 0.176 & 0.86 & 0.0075 & 81 & 6.1 & 1.15 & 2.08 & 0.00003 \\
\hline 35 & 8.2 & 0.338 & 0.86 & 0.008 & 82 & 6 & 0.58 & 2.08 & 0.0012 \\
\hline 36 & 6.8 & 1 & 0.90 & 0.003 & 83 & 7 & 0.441 & 2.125 & 0.0045 \\
\hline 37 & 7 & 0.5 & 0.93 & 0.0006 & 84 & 8.1 & 0.65 & 2.25 & 0.00033 \\
\hline 38 & 7.1 & 0.5 & 1.06 & 0.03 & 85 & 7.3 & 1 & 2.32 & 0.0014 \\
\hline 39 & 6.2 & 0.77 & 1.15 & 0.0007 & 86 & 5.9 & 2.077 & 3.37 & 0.0003 \\
\hline 40 & 7.3 & 1.37 & 1.18 & 0.0008 & 87 & 6.2 & 0.65 & 3.375 & 0.0002 \\
\hline 41 & 6.8 & 0.9 & 1.18 & 0.0026 & 88 & 7 & 1.30769 & 3.37500 & 0.00056 \\
\hline 42 & 6.8 & 0.18 & 1.18 & 0.0184 & 89 & 6.6 & 7.66667 & 3.69697 & 0.00001 \\
\hline 43 & 6.6 & 0.289 & 1.18 & 0.036 & 90 & 7.3 & 1.00000 & 4.64706 & 0.00041 \\
\hline 44 & $7 \mathrm{cs}$ & 0 & 1.3125 & 0.758 & 91 & 6 & 1.53333 & 4.88000 & 0.00001 \\
\hline 45 & 7.3 & 1.33 & 1.35 & 0.00002 & 92 & 5.1 & 7.66667 & 4.88000 & 0.00001 \\
\hline 46 & 6.7 & 0.25 & 1.41 & 0.0008 & 93 & 7.5 & 1.00000 & 4.93750 & 0.00014 \\
\hline 47 & 6.6 & 0.316 & 1.41 & 0.006 & 94 & 7.8 & 0.66667 & 0.11667 & 0.13696 \\
\hline 48 & 7 & 0.348 & 1.44 & 0.0039 & 95 & 7.8 & 0.44444 & 0.11667 & 0.28000 \\
\hline 49 & 7.5 & 5.6 & 1.46 & 0.00001 & 96 & 8.1 & 0.15000 & 0.12857 & 0.33333 \\
\hline 50 & 6.4 & 0.72 & 1.48 & 0.0004 & 97 & 7.7 & 0.00000 & 0.13333 & 0.63500 \\
\hline 51 & 5.5 & 0 & 1.48 & 0.185 & 98 & 7.8 & 0.22222 & 0.15000 & 0.41538 \\
\hline 52 & 7.6 & 0.138 & 1.5 & 0.00003 & 99 & 7.9 & 0.00000 & 0.18519 & 0.51600 \\
\hline 53 & 7.6 & 0.18 & 1.5 & 0.00004 & 100 & 7.9 & 0.00000 & 0.23333 & 1.35870 \\
\hline 54 & 7.6 & 0.288 & 1.5 & 0.0003 & 101 & 5.9 & 2.50000 & 3.76000 & 0.00040 \\
\hline 55 & 7.6 & 0.48 & 1.5 & 0.0118 & 102 & 5.7 & 23.00000 & 3.81250 & 0.00001 \\
\hline 56 & 7.1 & 1.038 & 1.5 & 0.00002 & 103 & 6.5 & 0.70833 & 3.85714 & 0.00115 \\
\hline 57 & 7.1 & 7 & 1.51 & 0.00001 & 104 & 7 & 1.53333 & 4.46875 & 0.00020 \\
\hline 58 & 7.1 & 1 & 1.53 & 0.00003 & 105 & 5.9 & 1.00000 & 4.64706 & 0.00027 \\
\hline 59 & 7.2 & 0 & 1.53 & 0.985 & 106 & 6 & 1.90909 & 10.96000 & 0.00003 \\
\hline 60 & 7.3 & 1.17 & 1.56 & 0.0019 & 107 & 7 & 0.28889 & 2.40625 & 0.00414 \\
\hline 61 & 7 & 1.03 & 1.59 & 0.00002 & 108 & 7 & 0.36207 & 2.46875 & 0.03670 \\
\hline 62 & 7.3 & 0.31 & 1.608 & 0.0009 & 109 & 8 & 1.12121 & 2.62000 & 0.00001 \\
\hline 63 & 6.8 & 0.66 & 1.65 & 0.0124 & 110 & 7.2 & 1.08333 & 2.82143 & 0.00044 \\
\hline 64 & 7.1 & 3.5 & 1.67 & 0.00002 & 111 & 7.6 & 0.82609 & 2.87273 & 0.00086 \\
\hline 65 & 6.9 & 1.31 & 1.68 & 0.00004 & 112 & 7.5 & 5.00000 & 2.93750 & 0.00200 \\
\hline 66 & 7.6 & 3 & 1.71 & 0.00022 & 113 & 4.6 & 1.00000 & 3.12000 & 0.00014 \\
\hline 67 & 6.6 & 0 & 1.78 & 0.24238 & 114 & 6.7 & 0.94444 & 3.28000 & 0.00031 \\
\hline
\end{tabular}


Table A.1. Summary of datasets used to develop Support Vector Regression (SVR)-based models (continued).

\begin{tabular}{|c|c|c|c|c|c|c|c|c|c|}
\hline No. & $M_{w}$ & $a_{y} / a_{\max }$ & $\boldsymbol{T}_{d} / \boldsymbol{T}_{p}$ & $S / H$ & No. & $M_{w}$ & $a_{y} / a_{\max }$ & $T_{d} / T_{p}$ & $S / H$ \\
\hline 115 & 7 & 1.50000 & 4.00000 & 0.00001 & 134 & 7.3 & 0.53333 & 1.40625 & 0.10000 \\
\hline 116 & 6.9 & 0.22727 & 0.46875 & 0.57692 & 135 & 7.6 & 0.22500 & 1.50000 & 0.12308 \\
\hline 117 & 6.9 & 0.10000 & 0.53125 & 0.27000 & 136 & 6.6 & 0.71429 & 2.25000 & 0.00273 \\
\hline 118 & 7 & 0.48485 & 0.59375 & 0.05607 & 137 & 7 & 0.58140 & 2.34375 & 0.00020 \\
\hline 119 & 6.9 & 0.17500 & 0.65625 & 0.16667 & 138 & 6 & 2.16667 & 2.76000 & 0.00001 \\
\hline 120 & 7.6 & 0.21429 & 0.75000 & 0.07333 & 139 & 5.6 & 0.57692 & 2.76000 & 0.00188 \\
\hline 121 & 8 & 0.72000 & 0.84000 & 0.01859 & 140 & 7.6 & 2.39130 & 2.87273 & 0.00031 \\
\hline 122 & 8.2 & 0.36250 & 0.86667 & 0.03077 & 141 & 7.3 & 0.36364 & 0.15625 & 0.18750 \\
\hline 123 & 7.5 & 1.75000 & 0.93506 & 0.00090 & 142 & 7.1 & 0.03030 & 0.15625 & 0.40000 \\
\hline 124 & 0.7 & 1.54545 & 1.12121 & 0.00005 & 143 & 7.8 & 0.00000 & 0.40000 & 0.97474 \\
\hline 125 & 8.2 & 4.18182 & 1.25000 & 0.00003 & 144 & 7.6 & 1.50000 & 0.42857 & 0.00125 \\
\hline 126 & 6.5 & 1.00000 & 1.29630 & 0.00004 & 145 & 8.1 & 0.84615 & 2.98113 & 0.00075 \\
\hline 127 & 7 & 0.00000 & 1.31250 & 0.72273 & 146 & 7 & 1.20000 & 3.09375 & 0.00002 \\
\hline 128 & 7.9 & 1.47368 & 1.38333 & 0.00412 & 147 & 8.3 & 0.21053 & 3.09375 & 0.01039 \\
\hline 129 & 6.9 & 0.46875 & 1.50000 & 0.00457 & 148 & 6.6 & 0.90909 & 3.12000 & 0.00028 \\
\hline 130 & 7.3 & 0.61111 & 1.68750 & 0.00003 & 149 & 7.8 & 0.30000 & 1.71154 & 0.03788 \\
\hline 131 & 6.7 & 0.34375 & 1.70370 & 0.00600 & 150 & 4.9 & 1.33333 & 3.48148 & 0.00040 \\
\hline 132 & 6.8 & 0.65455 & 1.75000 & 0.00045 & 151 & 4.5 & 7.66667 & 3.81250 & 0.00001 \\
\hline 133 & 4.8 & 10.00000 & 2.04000 & 0.00002 & & & & & \\
\hline
\end{tabular}

\section{Biographies}

Hamed Javdanian is currently a faculty member of Shahrekord University, Shahrekord, Iran, where he is working as a Senior Geotechnical Engineer and the Head of the Civil Engineering Department. His professional research interests include geotechnical earthquake engineering, foundation engineering, and soil improvement. He has published many papers. Dr. Javdanian is a member of the International Society for Soil Mechanics and Geotechnical Engineering (ISSMGE) and the Iranian Geotechnical Society (IGS). He is also a member of the research committee of several construction engineering companies in Iran.

Hamed Reza Zarif Sanayei is an Assistant Professor at the Department of Civil Engineering, Shahrekord University, Shahrekord, Iran. His research interests are computational hydraulics, turbulence flow, numerical modeling in open channel hydraulics, computational river dynamics, and computational hydrodynamics. $\mathrm{He}$ is the author and co-author of several papers in international and national journals and conferences. He is actively involved in teaching, research and consulting works in areas of water research and hydraulic structures.

Leila Shakarami is currently an MSc student at the Department of Civil Engineering, Shahrekord University, Shahrekord, Iran. Her research interests are mainly in the area of hydraulic structures, with special focus on earthquake-induced behavior of earth dams. 